\title{
RNA-Seq reveals differential expression profiles and functional annotation of genes involved in retinal degeneration in Pde6c mutant Danio rerio
}

\author{
Madhu Sudhana Saddala ${ }^{1,2}$, Anton Lennikov ${ }^{1,2}$, Adam Bouras $^{1}$ and Hu Huang ${ }^{1,2^{*}}$ (D)
}

\begin{abstract}
Background: Retinal degenerative diseases affect millions of people and represent the leading cause of vision loss around the world. Retinal degeneration has been attributed to a wide variety of causes, such as disruption of genes involved in phototransduction, biosynthesis, folding of the rhodopsin molecule, and the structural support of the retina. The molecular pathogenesis of the biological events in retinal degeneration is unclear; however, the molecular basis of the retinal pathological defect can be potentially determined by gene-expression profiling of the whole retina. In the present study, we analyzed the differential gene expression profile of the retina from a wild-type zebrafish and phosphodiesterase 6c (pde6c) mutant.
\end{abstract}

Results: The datasets were downloaded from the Sequence Read Archive (SRA), and adaptors and unbiased bases were removed, and sequences were checked to ensure the quality. The reads were further aligned to the reference genome of zebrafish, and the gene expression was calculated. The differentially expressed genes (DEGs) were filtered based on the log fold change (logFC) $( \pm 4)$ and $p$-values $(p<0.001)$. We performed gene annotation (molecular function [MF], biological process [BP], cellular component [CC]), and determined the functional pathways Kyoto Encyclopedia of Genes and Genomes (KEGG) pathway for the DEGs. Our result showed 216 upregulated and 3527 downregulated genes between normal and pde6c mutant zebrafish. These DEGs are involved in various KEGG pathways, such as the phototransduction (12 genes), mRNA surveillance (17 genes), phagosome (25 genes), glycolysis/gluconeogenesis (15 genes), adrenergic signaling in cardiomyocytes (29 genes), ribosome (20 genes), the citrate cycle (TCA cycle; 8 genes), insulin signaling (24 genes), oxidative phosphorylation (20 genes), and RNA transport (22 genes) pathways. Many more of all the pathway genes were down-regulated, while fewer were up-regulated in the retina of pde6c mutant zebrafish.

Conclusions: Our data strongly indicate that, among these genes, the above-mentioned pathways' genes as well as calcium-binding, neural damage, peptidase, immunological, and apoptosis proteins are mostly involved in the retinal and neural degeneration that cause abnormalities in photoreceptors or retinal pigment epithelium (RPE) cells.

Keywords: Pde6c, Zebrafish, Gene ontology, FastQC, Trinity, KEGG

\footnotetext{
* Correspondence: huangh1@missouri.edu

${ }^{1}$ School of Medicine, Department Ophthalmology, Mason Eye Institute,

University of Missouri-Columbia, One Hospital Drive, MA102C, Columbia, MO 65212, USA

2Wilmer Eye Institute, Johns Hopkins University, Baltimore, MD, USA
}

(c) The Author(s). 2020 Open Access This article is distributed under the terms of the Creative Commons Attribution 4.0 International License (http://creativecommons.org/licenses/by/4.0/), which permits unrestricted use, distribution, and reproduction in any medium, provided you give appropriate credit to the original author(s) and the source, provide a link to the Creative Commons license, and indicate if changes were made. The Creative Commons Public Domain Dedication waiver (http://creativecommons.org/publicdomain/zero/1.0/) applies to the data made available in this article, unless otherwise stated. 


\section{Background}

Retinal degeneration is retinopathy that consists of the deterioration of the retina due to the progressive death of its cells [1]. It is a common cause of blindness, and it can result from mutations in a large variety of structural and enzymatic proteins of the photoreceptors [2]. Degenerative diseases of the retina, including retinitis pigmentosa (RP), affect nearly 2 million patients worldwide [3]. A wide variety of causes have been attributed to retinal degeneration, such as disruption of the genes involved in phototransduction, biosynthesis, folding of the rhodopsin molecule, and the structural support of the retina [4]. In zebrafish mutants, an A > G point mutation was identified in the pde6c (phosphodiesterase 6C, cyclic guanosine monophosphate [cGMP]-specific, cone, alpha prime) gene [5]. This gene encodes the beta subunit of the phosphodiesterase 6 (Pde6) protein, which is essential for the proper functioning of the photoreceptor cells [6]. The beta subunit is one of two catalytic subunits of the pde6 protein, which combines with two inhibitory gamma subunits to form the effector enzyme of rod phototransduction [7]. Light stimulation triggers a cascade of reactions, leading to the hydrolysis of cGMP by pde6, and the resulting change in cGMP concentration directly alters the membrane channels to produce the electrical response of the photoreceptors [7]. Due to the high cooperativity of cGMP binding to the channel [8], a small increase in cGMP levels will have a profound effect on the number of open channels and the cations $\left(\mathrm{Na}^{+}\right.$, $\mathrm{Ca}^{2+}$ ) that pass through them. Humans harboring loss-offunction PDE6b mutations develop RP, progressing to total blindness as a function of age $[9,10]$. This mutation has been predicted to cause a frameshift in the coding sequence and result either in a truncated pde6c or degradation of pde6c mRNA through nonsense-mediated decay; it ultimately affects both cone and rod photoreceptors [7]. Human PDE6c mutations have been reported and linked to autosomal recessive achromatopsia [11, 12]. Moreover, the PDE6c mutant zebrafish was introduced as a model organism that recapitulates many properties of human PDE6c patients [7]. These animals develop rapid photoreceptor cell loss that progresses with age and is followed by complete loss of visual functions. Understanding which genes are perturbed in the photoreceptor degeneration could pave the way for the identification of biomarkers as potential predictors of disease onset, as well as elucidating the pathways involved in the degenerative process, as the zebrafish as a model organism that allows rapid screening of a multitude of substances and therapeutic approaches.

In this study, we used publicly available pde6c mutant and wild type zebrafish retina whole transcriptome shotgun sequencing (RNA-Seq) datasets [13] to examine differentially expressed genes (DEGs), gene ontology (GO), and functional pathway analysis. We seek to characterize the signal pathways and genes that are potentially involved in retinal degeneration in general and photoreceptor degeneration in particular, as well as to better understand the molecular mechanisms that underlie the retinal degenerative disorders by using transcriptomic and bioinformatics approaches.

\section{Results \\ Differential gene expression analysis}

We discovered 216 up-regulated and 3527 downregulated DEGs in the pde6c mutant conditions. The hierarchical clustering heatmap, MA plot, and volcano plots were generated to represent the up- and down-regulated genes $(\log \mathrm{FC} \pm 4$ and $p<0.001)$. Figure 1a represents the heatmap of up- and down-regulated genes in orange and blue, respectively. The volcano plot (Fig. 1b) and the MA plot (Fig. 1c) visualizes the differences between measurements taken in wild and mutant zebrafish DEGs. The gene density is presented in Fig. 2, demonstrating all parts of the genes, such as the coding sequence length, transcript length, genome span, 5' UTR length, 3' UTR length, and percentage of GC content compared with the zebrafish genome's density. The results revealed that all the parts of the gene's density (List, DEGs) fluctuate compared with the zebrafish genome. Also, we predicted the distribution of DEGs on zebrafish chromosomes (genome-wide distribution), distribution of gene type, number of exons (coding genes), and number of transcript isoforms per coding gene. Figure 3a revealed that all the query genes were distributed on 25 chromosomes, and the mitochondria genome of zebrafish with the exception of chromosome 4. Figure $3 \mathrm{~b}$ shows that the protein-coding (mRNA) was more distributed than the others, while Fig. $3 \mathrm{c}$ shows that exon 4 is more distributed among the number of genes, and Fig. 3d shows that one and two transcripts per gene are equally distributed among the number of genes.

\section{Functional annotation}

All the DEGs were uploaded to the GO Enrichment Analysis tool and database for annotation, visualization and integrated discovery (DAVID) tool using the complete zebrafish genome as the background. The molecular functions (MFs), biological processes (BPs), cellular components (CCs), and pathways were predicted in the significantly enriched GO terms of the differentially express genes (Fig. 4). The DEGs were involved in various MFs, such as small molecule binding (GO: 0036094; FDR $=6.33 \mathrm{e}-11), \quad$ nucleotide-binding $\quad(\mathrm{GO}: \quad 0000166$; FDR $=6.52 \mathrm{e}-11$ ), nucleoside phosphate binding (GO: 1901265; $F D R=6.52 \mathrm{e}-11$ ), cation-transporting ATPase activity (GO: 0019829; FDR =1.34e-08), ATPase-coupled ion transmembrane transporter activity (GO: 0042625; $\mathrm{FDR}=1.34 \mathrm{e}-08)$, active ion transmembrane transporter activity (GO: 0022853; FDR $=2.33 \mathrm{e}-08$ ), purine nucleotide binding (GO: 0017076; FDR $=2.43 \mathrm{e}-08$ ), purine 


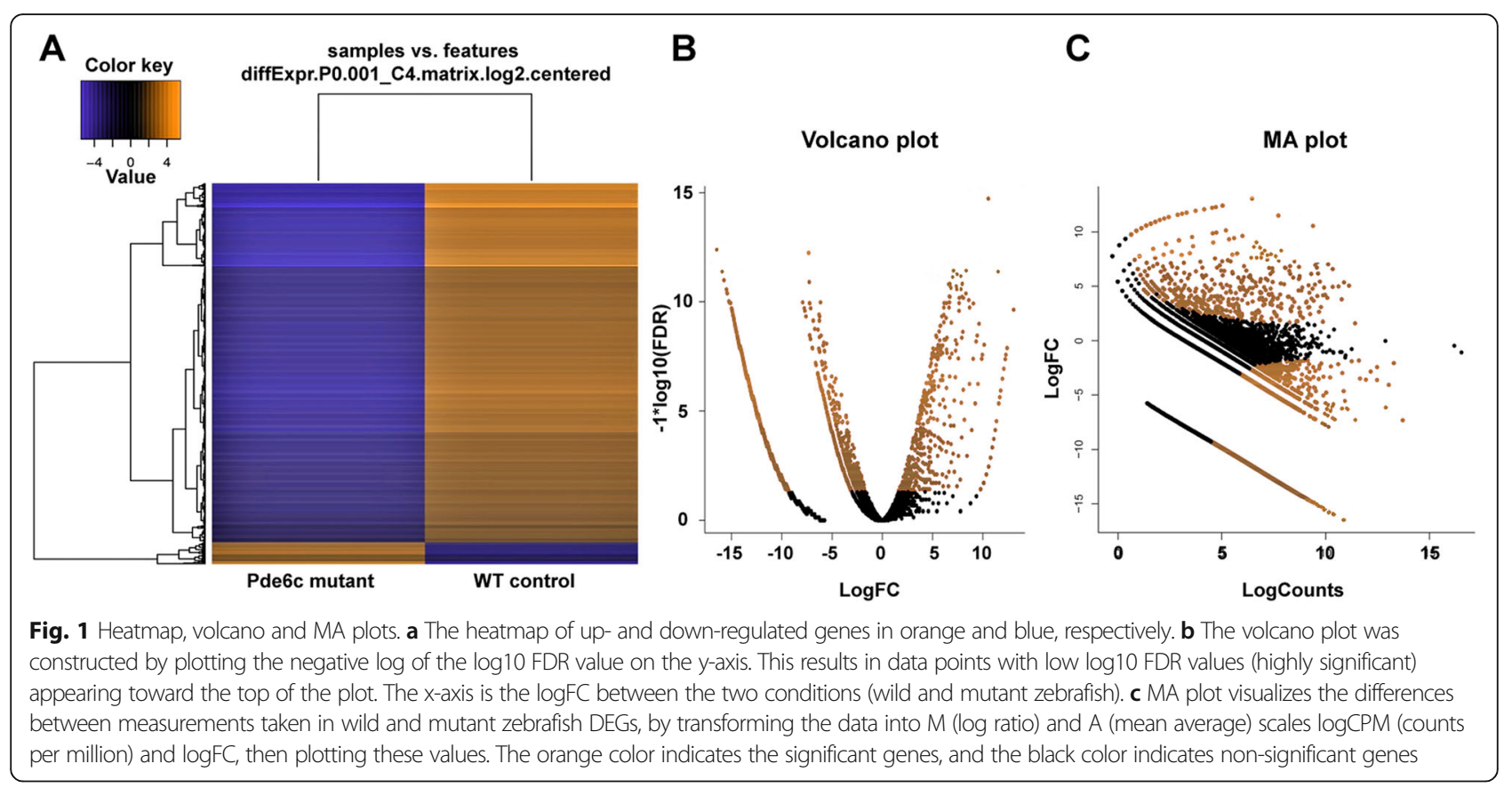

ribonucleotide binding (GO: 0032555; $F D R=3.78 \mathrm{e}-08$ ), nucleoside binding (GO: 0001882; FDR $=3.78 \mathrm{e}-08$ ), and ribonucleotide binding (GO: 0032553; FDR $=4.45 \mathrm{e}-08$ ) functions. Among these MFs, most of the genes are involved in small molecule binding (171 genes), and nucleoside phosphate binding (164 genes) functions.

The DEGs are involved in various BPs, such as embryo development $(\mathrm{GO}: \quad 0009790 ; \quad F D R=5.81 \mathrm{e}-11)$, retina development in camera-type eyes (GO: 0060041; FDR = 2.48e-10), system development (GO: 0048731; FDR = $2.48 \mathrm{e}-10$ ), embryo development ending in birth or egg hatching (GO: 0009792; FDR $=2.48 \mathrm{e}-10$ ), chordate embryonic development (GO: 0043009; FDR $=2.48 \mathrm{e}-10$ ), animal organ development (GO: 0048513; FDR $=6.93 \mathrm{e}-10$ ), eye development (GO: 0001654; FDR = 2.44e- 09), camera-type eye development (GO: 0043010; FDR $=5.81 \mathrm{e}-09$ ), sensory

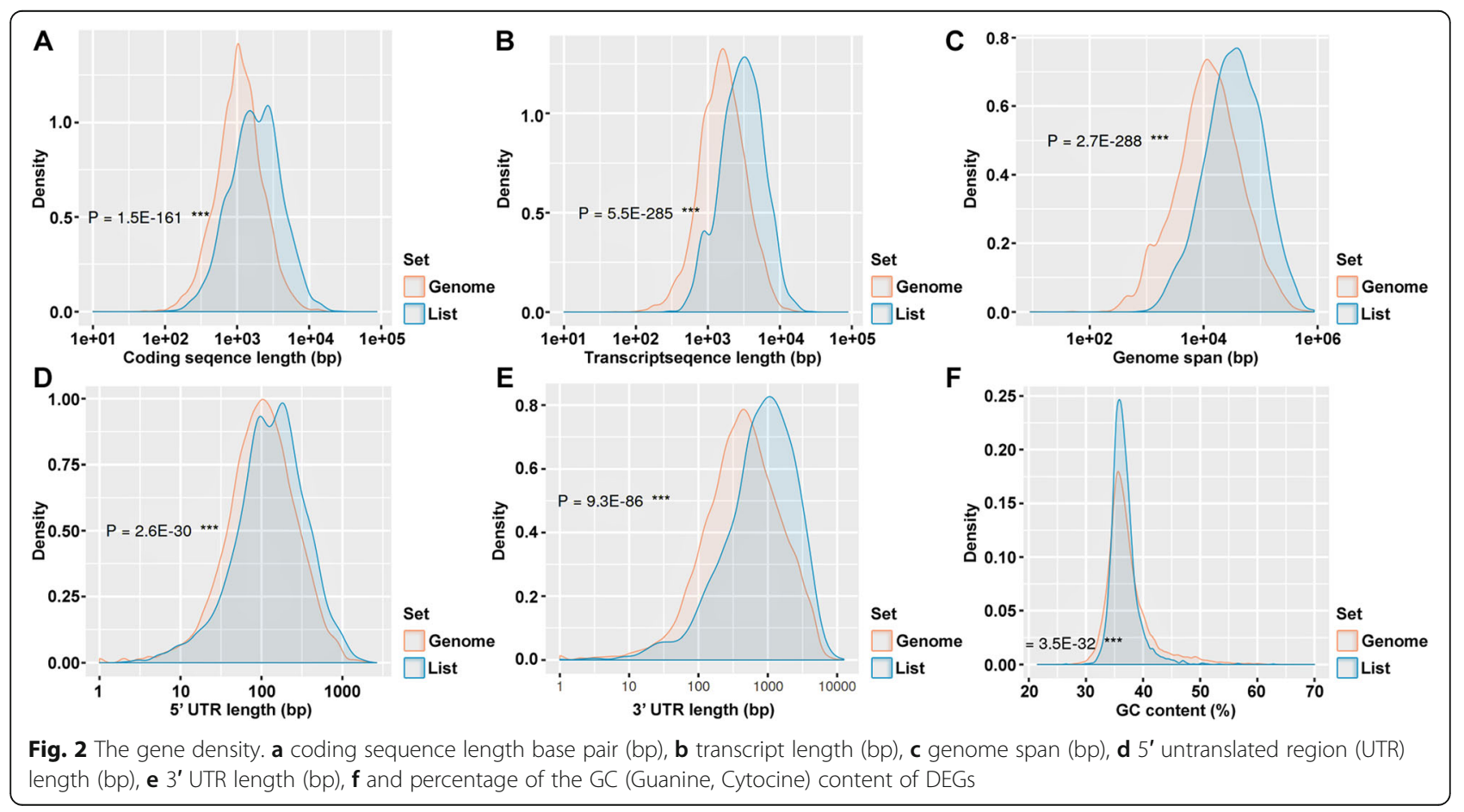



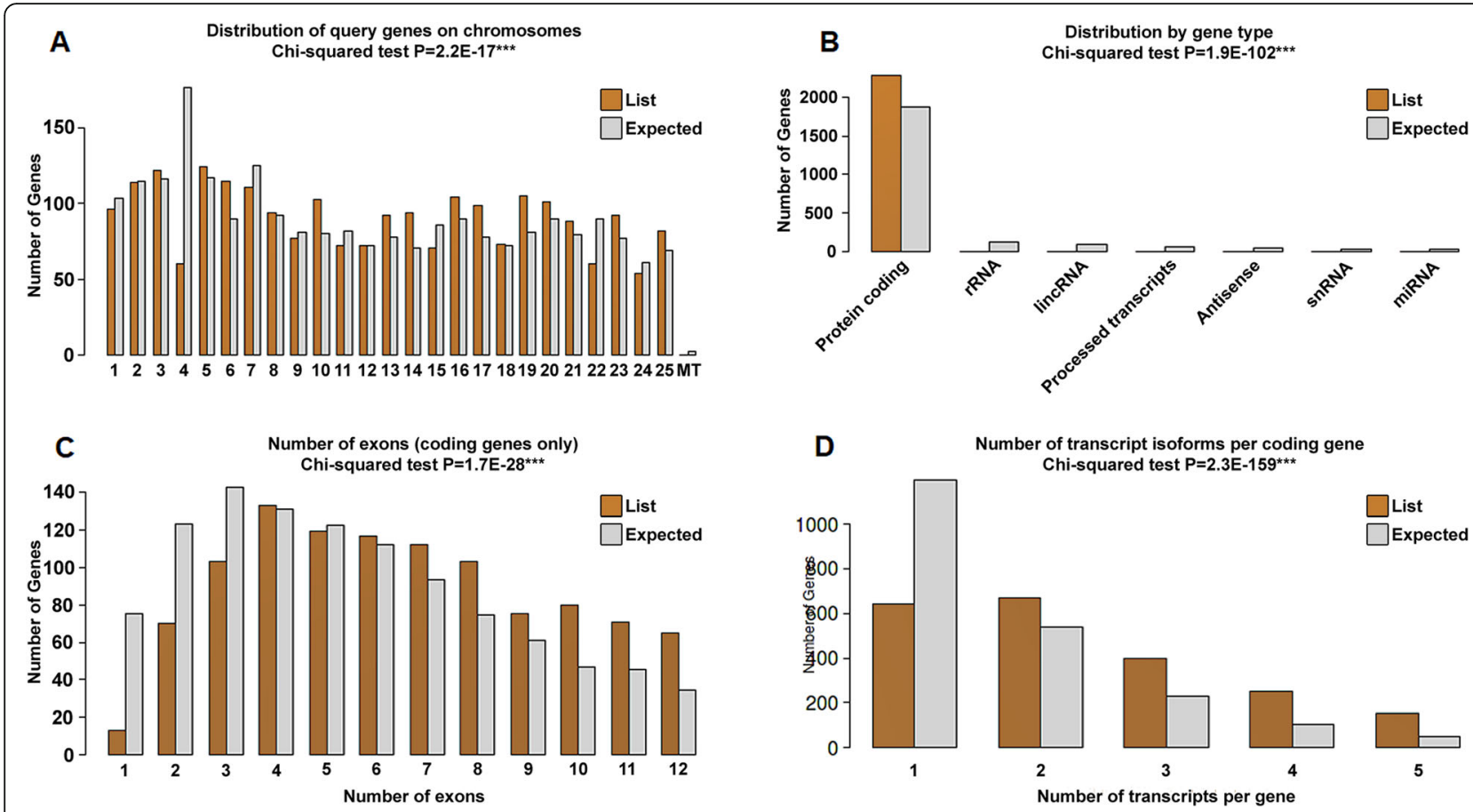

Fig. 3 Genome-wide distribution of DEGs on zebrafish chromosomes. a Distribution of query genes across 25 chromosomes of zebrafish and mitochondria genome. $\mathbf{b}$ Distribution by gene type. $\mathbf{c}$ Distribution of genes through the exons. $\mathbf{d}$ Number of transcripts isoforms per coding gene

organ development (GO:0007423; FDR $=1.62 \mathrm{e}-07)$, and the cellular developmental process (GO: 0048869; FDR $=9 \mathrm{e}$ - 07). Among these BPs, most genes are involved in system development (184 genes), animal organ development (141 genes), and cellular developmental processes (121 genes).

The DEGs are involved in various CCs, such as the macromolecular complex (GO: 0032991; FDR $=0 \mathrm{e}+00$ ), cytosol (GO: 0005829; $F D R=2.18 \mathrm{e}-12$ ), cell periphery (GO: 0071944; FDR $=1.61 \mathrm{e}-11$ ), plasma membrane (GO: 0005886; FDR = 1.61e- 11), protein complex (GO: 0043234; $\mathrm{FDR}=1.61 \mathrm{e}-11)$, membrane protein complex (GO: 0098796; $F D R=9.62 \mathrm{e}-11$ ), neuron part (GO: 0097458; $\mathrm{FDR}=3.74 \mathrm{e}-10)$, plasma membrane part (GO: 0044459; FDR $=3.84 \mathrm{e}-10)$, whole membrane (GO: 0098805; FDR = 5.66e-10), and non-membrane-bounded organelle (GO: 0043228; FDR $=1.24 \mathrm{e}-08$ ) functions. Most genes are involved in the macromolecular complex (169 genes), cell periphery (107 genes), and plasma membrane (105 genes).

\section{Pathway analysis}

Pathway analysis helps elucidate data from canonical prior knowledge structured in the form of pathways. It allows finding distinct cell processes, diseases, or signaling pathways that are statistically associated with the selection of DEGs [14]. The DEGs are further analyzed in the pathway functional analysis using the DAVID annotation tool (Fig. 5). They are involved in various KEGG pathways, such as the phototransduction (12 genes),
mRNA surveillance (17 genes), phagosome (25 genes), glycolysis/gluconeogenesis (15 genes), adrenergic signaling in cardiomyocytes (29 genes), ribosome (20 genes), citrate cycle (TCA cycle; 8 genes), insulin signaling (24 genes), oxidative phosphorylation (20 genes), and RNA transport (22 genes) pathways. Most genes are involved in adrenergic signaling in the cardiomyocyte ( 29 genes), phagosome (25 genes), insulin signaling (24 genes), and RNA transport pathways (20 genes).

In this study, we focus on the phototransduction (dre04744; Table 1), phagosome (dre04145; Table 2), glycolysis/gluconeogenesis (dre00010; Table 3) and insulin signaling pathways (dre04910; Table 4).

\section{Gene network analysis}

The DEGs were used to construct gene-gene interactions using the STRING tool (https://string-db.org/), which also hides the disconnected nodes in the network. The results showed the analyzed number of nodes (426), expected number of edges (1235), the number of edges (1512), average node degree (7.1), average local clustering coefficient (0.363), and Protein-protein interaction (PPI) enrichment $p<1.58 \mathrm{e}-14$. We constructed the gene-gene network for DEGs with their respective minimum required interaction score (0.400). We mapped the phagosome (red), glycolysis/gluconeogenesis (blue), and insulin signaling (green) pathway genes' interaction in the global network (Additional file 1: Figure S1). These 


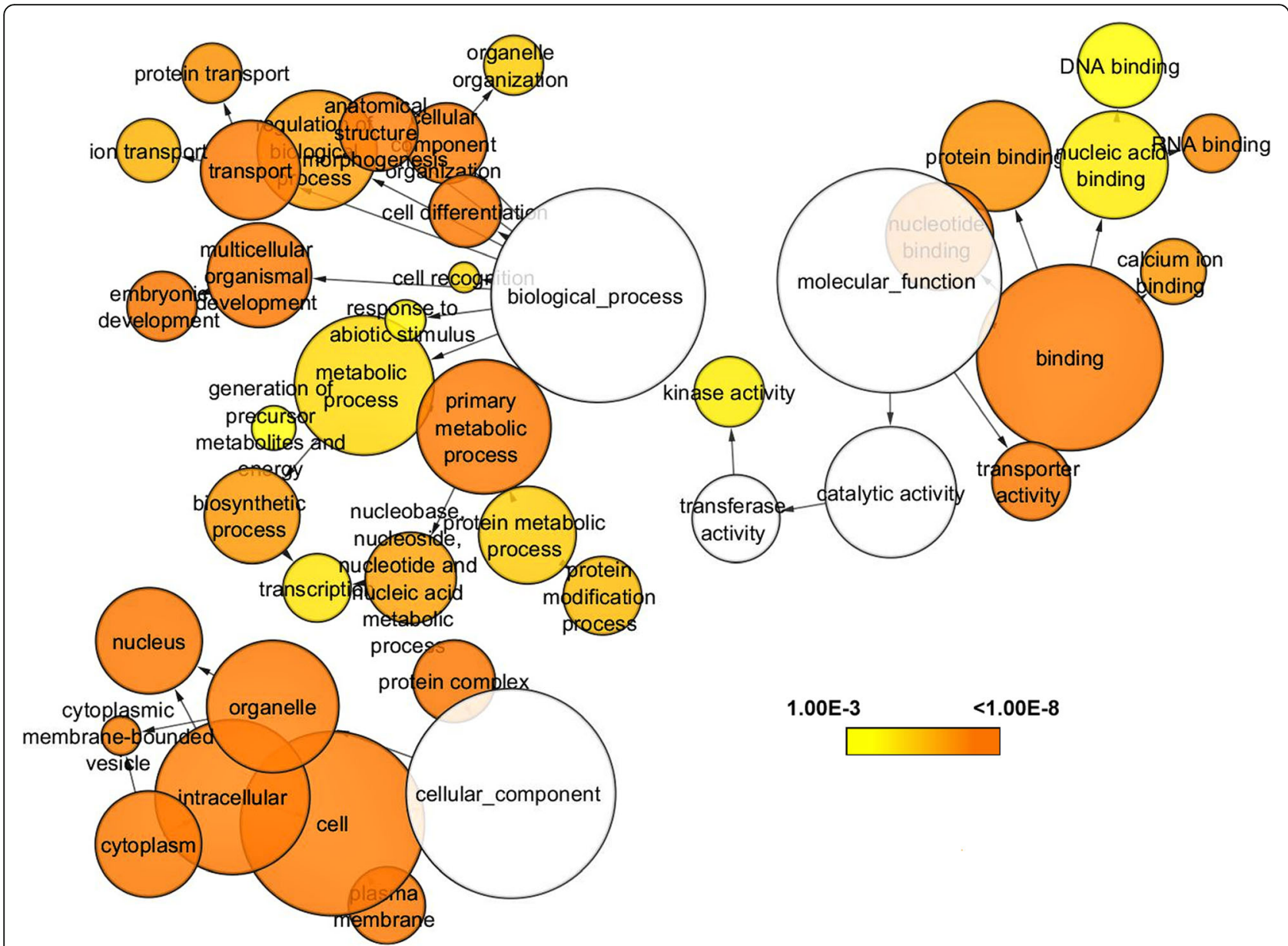

Fig. 4 Gene Ontology enrichment analysis like biological process (BP), cellular component (CC) and molecular functions (MF)

pathways genes interactions are presented individually as subnetworks. The phototransduction pathway subnetwork showed the number of nodes as 11, expected number of edges as 1, real number of edges as 32, average node degree as 5.82, average local clustering coefficient as 0.743 , and PPI enrichment as $p<1.0 \mathrm{e}-16$. The subnetwork results suggested that all the genes involved were directly connected and involved in the phototransduction pathway (Fig. 6a). The phagosome pathway genes' subnetwork results showed the number of nodes as 25 , expected number of edges as 16 , real number of edges as 83 , average node degree as 6.64 , average local clustering coefficient as 0.803 , and PPI enrichment as $p<1.0 \mathrm{e}-16$. This subnetwork genes' interaction results showed that the cybb (cytochrome b-245 beta) gene did not interact with any genes, but the remaining genes connected directly or indirectly to each other. This gene (cybb) may be involved individually in the phagosome pathway (Fig. 6b). The glycolysis/gluconeogenesis pathway subnetwork showed the number of nodes as 15 , expected number of edges as 3 , real number of edges as 65 , average node degree as 8.67 , average local clustering coefficient as 0.741 , and PPI enrichment as $p<1.0 \mathrm{e}-16$. These subnetwork results suggested that all the genes involved were directly connected and involved in the glycolysis/gluconeogenesis pathway (Fig. 6c). The insulin signaling pathway subnetwork showed the number of nodes as 23 , expected number of edges as 44 , the real number of edges as 87 , average node degree as 5.57 , average local clustering coefficient as 0.585 , and PPI enrichment as $p<6.47 \mathrm{e}-09$. These subnetwork results suggested that the flot2a (flotillin-2a) and mknk2b (MAPK interacting serine/threonine kinase $2 \mathrm{~b}$ ) genes are not connected to any genes, but the other genes are connected directly or indirectly (Fig. 6d). The flot2a and mknk2b genes are involved in the insulin signaling pathway individually.

\section{Discussion}

We provide a comprehensive transcriptomic analysis of wild and mutant zebrafish retina datasets. This approach may provide a gene expression profile for the wild-type and pdec6c mutant zebrafish retinal models. Mapping the genes and its expression values to the heatmap, 


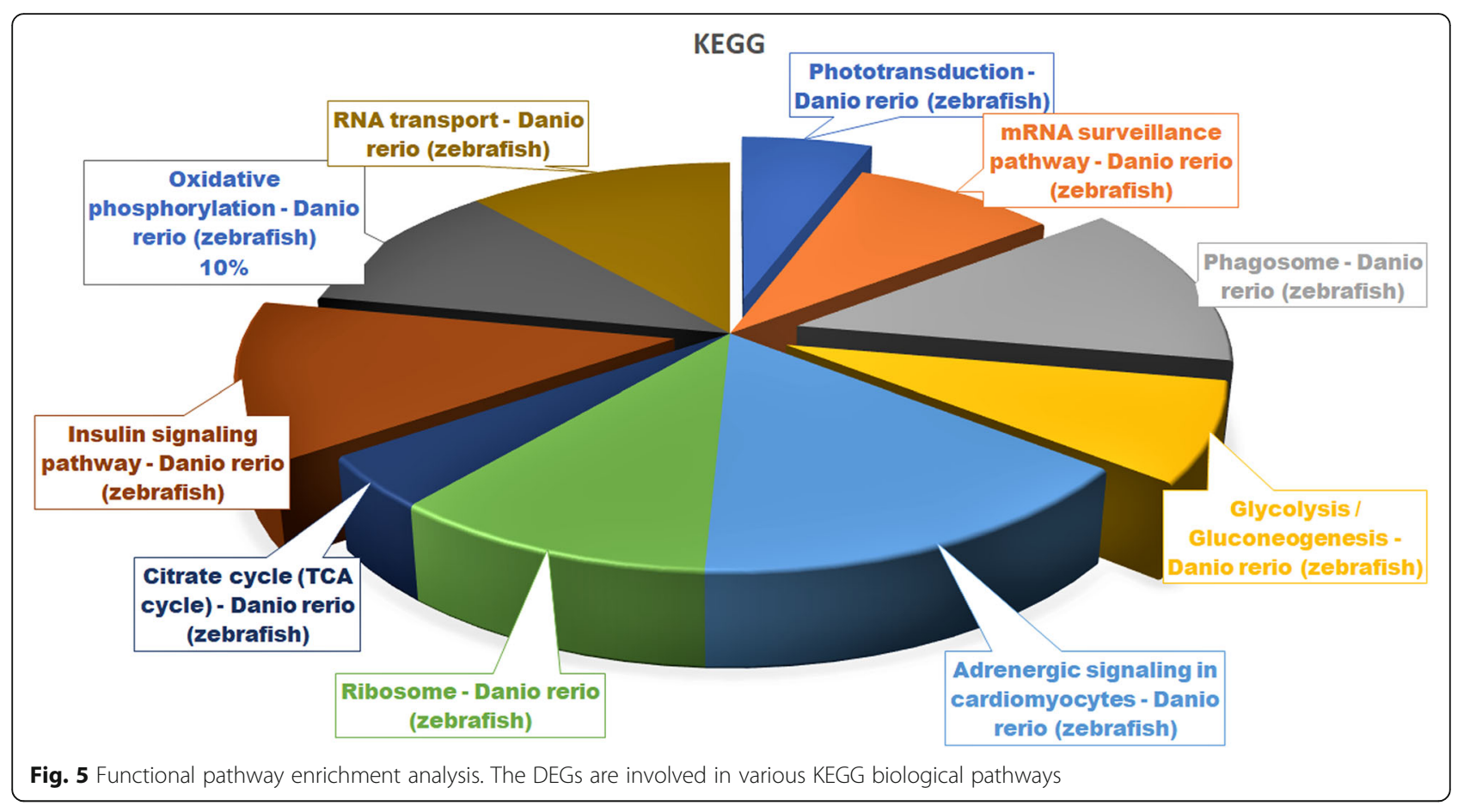

volcano and MA plots demonstrated clear separation between wild-type and pdec6c mutant zebrafish with the predominance of the down-regulated genes in the latter indicating it's a crucial role in the retinal cells function.

The pathway enrichment analysis and gene-gene network analysis revealed that the DEGs are involved in various KEGG functional pathways, such as the phototransduction, phagosome, glycolysis/gluconeogenesis, and insulin signaling pathways. Twelve genes are involved in the phototransduction pathway and downregulated in pde6c mutant zebrafish. Zhang et al. [13] reported the role of the phototransduction pathway genes in retinal degeneration. Stearns et al. [7] described how the mutation of the pde6 gene causes rapid cone photoreceptor degeneration in the zebrafish model. Our results also strongly correlated with the above-lighted findings.

Seventeen genes are involved in the phagosome pathway and down-regulated in the pde6c mutant. These genes interact with each other and are involved in retinal degeneration. Among these genes, the v-ATPase gene is essential for secretion, lysosome function, vesicular traffic, and phagocytosis [15]. In the zebrafish eye, VATPase regulates retinoblastoma proliferation and survival, possibly through the acidification resulting from proton accumulation [16]. The same $\mathrm{H}^{+}$proton pump is

Table 1 List of genes involved in Phototransduction pathway of Pde6c mutant zebrafish ( $p$-value $=0.0014000 ; F D R=0.0039000$ )

\begin{tabular}{|c|c|c|c|c|}
\hline Ref mRNA & Gene Symbol & Gene Name & $\log \mathrm{FC}$ & $p$-value \\
\hline NM_001007160 & pde6a & phosphodiesterase 6A, cGMP-specific, rod, alpha & -12.88482348 & $9.29 \mathrm{E}-08$ \\
\hline NM_001017711 & grk1b & $\mathrm{G}$ protein-coupled receptor kinase $1 \mathrm{~b}$ & -15.21450566 & $1.36 \mathrm{E}-13$ \\
\hline NM_001030248 & revrna & recoverin a & -14.7635283 & 1.67E-12 \\
\hline NM_001031841 & grk7a & G protein-coupled receptor kinase $7 a$ & -14.51580863 & $8.55 \mathrm{E}-12$ \\
\hline NM_001034181 & grk1a & G protein-coupled receptor kinase $1 \mathrm{a}$ & -5.203467963 & $2.80 \mathrm{E}-06$ \\
\hline NM_001327800 & rgs9a & regulator of $\mathrm{G}$ protein signaling $9 \mathrm{a}$ & -5.215468297 & $1.45 \mathrm{E}-08$ \\
\hline NM_131084 & rho & rhodopsin & -6.296723464 & 8.77E-13 \\
\hline NM_131868 & gnat1 & guanine nucleotide binding protein (G protein), alpha transducing activity polypeptide 1 & -7.218093348 & $2.15 \mathrm{E}-13$ \\
\hline NM_131869 & gnat2 & guanine nucleotide binding protein (G protein), alpha transducing activity polypeptide 2 & -4.074631105 & 4.60E-08 \\
\hline NM_199570 & calm3b & calmodulin 3b (phosphorylase kinase, delta) & -14.42999547 & 1.49E-11 \\
\hline NM_199996 & calm2a & calmodulin 2a (phosphorylase kinase, delta) & -13.04988312 & $3.41 \mathrm{E}-08$ \\
\hline NM_213481 & gnb1b & guanine nucleotide binding protein ( $\mathrm{G}$ protein), beta polypeptide $1 \mathrm{~b}$ & -13.12286971 & 2.17E-08 \\
\hline
\end{tabular}


Table 2 List of genes involved in phagosome pathway of pde6c mutant zebrafish ( $p$-value $=5.68 \mathrm{e}-04$; FDR $=2.6 \mathrm{e}-02$ )

\begin{tabular}{|c|c|c|c|c|}
\hline Ref mRNA & Gene Symbol & Gene Name & $\log F C$ & $p$-value \\
\hline NM_001033721 & itgav & integrin, alpha $V$ & -11.90966981 & $8.44 \mathrm{E}-06$ \\
\hline NM_153659 & sec61a1 & Sec61 translocon alpha 1 subunit & -4.751020073 & 2.47E-07 \\
\hline NM_173254 & atp6r1e1b & ATPase, $\mathrm{H}+$ transporting, lysosomal, V1 subunit E1b & -5.280581114 & 1.80E-06 \\
\hline NM_173255 & atp6v0ca & ATPase, $\mathrm{H}+$ transporting, lysosomal, VO subunit ca & -13.63501996 & 1.50E-09 \\
\hline NM_199561 & atp6v0b & ATPase, $\mathrm{H}+$ transporting, lysosomal V0 subunit b & -12.22047943 & $1.52 \mathrm{E}-06$ \\
\hline NM_199620 & atp6v0d1 & ATPase, $\mathrm{H}+$ transporting, lysosomal V0 subunit d1 & -12.91329746 & 7.59E-08 \\
\hline NM_199713 & calr & calreticulin & -11.48042737 & 4.49E-05 \\
\hline NM_199934 & atp6v1g1 & ATPase, $\mathrm{H}+$ transporting, lysosomal, V1 subunit G1 & -12.06864677 & $3.55 \mathrm{E}-06$ \\
\hline NM_201485 & rab5aa & RAB5A, member RAS oncogene family, a & -12.76579558 & 1.10E-07 \\
\hline NM_201322 & atp6v1c1a & ATPase, $\mathrm{H}+$ transporting, lysosomal, V1 subunit C1a & -12.8196416 & 7.94E-08 \\
\hline NM_194388 & tuba1b & tubulin, alpha $1 \mathrm{~b}$ & -11.23913699 & $8.52 \mathrm{E}-05$ \\
\hline NM_198818 & tubb5 & tubulin, beta 5 & -4.073625492 & 4.71E-05 \\
\hline NM_200414 & cybb & cytochrome b-245, beta polypeptide (chronic granulomatous disease) & 5.802066863 & $3.87 \mathrm{E}-12$ \\
\hline NM_201135 & atp6v1aa & ATPase, $\mathrm{H}+$ transporting, lysosomal, V1 subunit Aa & -13.31681197 & $6.58 \mathrm{E}-09$ \\
\hline NM_213030 & tuba2 & tubulin, alpha 2 & -12.88637707 & 8.98E-08 \\
\hline NM_213448 & $\operatorname{can} x$ & calnexin & -12.86210644 & $6.21 \mathrm{E}-08$ \\
\hline NM_001002526 & atp6r1f & ATPase, $\mathrm{H}+$ transporting, lysosomal, $\mathrm{V} 1$ subunit $\mathrm{F}$ & -11.68530135 & 1.63E-05 \\
\hline NM_001005772 & atp6v1c1b & ATPase, $\mathrm{H}+$ transporting, lysosomal, $\mathrm{V} 1$ subunit $\mathrm{C} 1 \mathrm{~b}$ & -11.19719131 & 0.000111091 \\
\hline NM_001020666 & atp6v0a1b & ATPase, $\mathrm{H}+$ transporting, lysosomal V0 subunit a1b & -13.28947797 & 7.71E-09 \\
\hline NM_001172635 & atpv0e2 & ATPase, $\mathrm{H}+$ transporting V0 subunit e2 & -12.58243475 & $3.26 \mathrm{E}-07$ \\
\hline NM_001082836 & itgb5 & integrin, beta 5 & -11.19217538 & 0.000111091 \\
\hline NM_001105126 & tuba1c & tubulin, alpha $1 \mathrm{c}$ & -14.61096727 & 4.55E-12 \\
\hline NM_131031 & actb1 & actin, beta 1 & -5.667990423 & 5.34E-09 \\
\hline NM_181601 & actb2 & actin, beta 2 & -4.641227854 & 5.35E-09 \\
\hline NM_001037410 & tubb2b & tubulin, beta $2 \mathrm{~b}$ & -5.70469418 & $6.49 \mathrm{E}-10$ \\
\hline
\end{tabular}

Table 3 List of genes involved in glycolysis/gluconeogenesis pathway of Pde6c mutant zebrafish ( $p$-value $=6.8 \mathrm{e}-04 ; \mathrm{FDR}=2.6 \mathrm{e}-02$ )

\begin{tabular}{|c|c|c|c|c|}
\hline Ref mRNA & Gene Symbol & Gene Name & $\log \mathrm{FC}$ & $p$-value \\
\hline NM_153667 & tpi1a & triosephosphate isomerase $1 \mathrm{a}$ & -12.15496243 & $2.18 \mathrm{E}-06$ \\
\hline NM_131246 & Idha & lactate dehydrogenase A4 & -13.07189634 & 2.92E-08 \\
\hline NM_131247 & Idhba & lactate dehydrogenase $\mathrm{Ba}$ & -13.11162313 & 2.30E-08 \\
\hline NM_212667 & dlat & dihydrolipoamide S-acetyltransferase (E2 component of pyruvate dehydrogenase complex) & -11.98410994 & $5.58 \mathrm{E}-06$ \\
\hline NM_201300 & pgam1b & phosphoglycerate mutase $1 \mathrm{~b}$ & -5.097181249 & $5.05 \mathrm{E}-06$ \\
\hline NM_212724 & aldh7a1 & aldehyde dehydrogenase 7 family, member $\mathrm{A} 1$ & -13.09492311 & 2.59E-08 \\
\hline NM_194377 & aldoaa & aldolase a, fructose-bisphosphate, a & -11.6637211 & $1.75 \mathrm{E}-05$ \\
\hline NM_214751 & pck1 & phosphoenolpyruvate carboxykinase 1 (soluble) & 5.129531889 & 7.55E-09 \\
\hline NM_201506 & dldh & dihydrolipoamide dehydrogenase & -12.15238215 & 2.18E-06 \\
\hline NM_213094 & gapdhs & glyceraldehyde-3-phosphate dehydrogenase, spermatogenic & -5.832123465 & 3.72E-11 \\
\hline NM_213387 & pgk1 & phosphoglycerate kinase 1 & -12.67163046 & 1.94E-07 \\
\hline NM_213252 & hk1 & hexokinase 1 & -13.41102831 & 3.67E-09 \\
\hline NM_001328389 & pfklb & phosphofructokinase, liver b & -11.29868758 & $6.58 \mathrm{E}-05$ \\
\hline NM_153668 & tpi1b & triosephosphate isomerase $1 b$ & -13.58805684 & 2.03E-09 \\
\hline NM_001080066 & $g 6 p c 3$ & glucose 6 phosphatase, catalytic, 3 & 4.465924297 & 9.85E-08 \\
\hline
\end{tabular}


Table 4 List of genes involved in insulin signalling pathway of Pde6c mutant zebrafish ( $p$-value $=5.64 \mathrm{e}-03$; FDR $=9.83 \mathrm{e}-02$ )

\begin{tabular}{|c|c|c|c|c|}
\hline Ref mRNA & Gene Symbol & Gene Name & $\log \mathrm{FC}$ & $p$-value \\
\hline NM_001004527 & ppp1cb & protein phosphatase 1, catalytic subunit, beta isozyme & -13.3391067 & 5.63E-09 \\
\hline NM_131855 & prkci & protein kinase $\mathrm{C}$, iota & -11.4865862 & 4.49E-05 \\
\hline NM_213075 & flot2a & flotillin $2 a$ & -11.94140373 & 7.05E-06 \\
\hline NM_001142672 & insra & insulin receptor a & -4.775105577 & $2.21 \mathrm{E}-05$ \\
\hline NM_001123229 & insrb & insulin receptor b & -11.53691235 & 3.33E-05 \\
\hline NM_131381 & gsk3b & glycogen synthase kinase 3 beta & -11.65098191 & 1.87E-05 \\
\hline NM_199570 & calm3b & calmodulin 3b (phosphorylase kinase, delta) & -14.42999547 & $1.49 \mathrm{E}-11$ \\
\hline NM_001077211 & mtor & mechanistic target of rapamycin (serine/threonine kinase) & -12.74710586 & $1.23 \mathrm{E}-07$ \\
\hline NM_212710 & ppp1cab & protein phosphatase 1 , catalytic subunit, alpha isozyme b & -4.868811067 & $1.31 \mathrm{E}-05$ \\
\hline NM_199996 & calm2a & calmodulin2a ( $p$ hosphorylase kinase, delta) & -13.04988312 & $3.41 \mathrm{E}-08$ \\
\hline NM_194402 & $m k n k 2 b$ & MAP kinase interacting serine/threonine kinase $2 \mathrm{~b}$ & -14.02356489 & $1.26 \mathrm{E}-10$ \\
\hline NM_214751 & pck1 & phosphoenolpyruvate carboxykinase 1 (soluble) & 5.129531889 & 7.55E-09 \\
\hline NM_200315 & irs2a & insulin receptor substrate $2 \mathrm{a}$ & -12.51373347 & 4.75E-07 \\
\hline NM_201023 & prkacba & protein kinase, cAMP-dependent, catalytic, beta a & 4.638063399 & $9.62 \mathrm{E}-09$ \\
\hline NM_205744 & braf & B-Raf proto-oncogene, serine/threonine kinase & -11.88966935 & $5.38 \mathrm{E}-06$ \\
\hline NM_213035 & grb2b & growth factor receptor-bound protein $2 \mathrm{~b}$ & -12.43630299 & 7.66E-07 \\
\hline NM_213076 & rps6kb1b & ribosomal protein $\mathbf{S 6}$ kinase b, polypeptide 1 b & -11.31030831 & $6.05 \mathrm{E}-05$ \\
\hline NM_213161 & prkag1 & protein kinase, AMP-activated, gamma 1 non-catalytic subunit & -11.20468266 & 0.000101616 \\
\hline NM_213252 & hk1 & hexokinase 1 & -13.41102831 & 3.67E-09 \\
\hline NM_001017732 & prkar1ab & $\begin{array}{l}\text { protein kinase, cAMP-dependent, regulatory, type I, alpha } \\
\text { (tissue specific extinguisher 1) b }\end{array}$ & -11.53493265 & $3.59 \mathrm{E}-05$ \\
\hline NM_001077370 & prkar2aa & protein kinase, cAMP-dependent, regulatory, type II, alpha A & -4.330637539 & 1.19E-05 \\
\hline NM_001281844 & pik3r1 & phosphoinositide-3-kinase, regulatory subunit 1 (alpha) & -13.92572365 & 2.37E-10 \\
\hline NM_131721 & mapk8b & mitogen-activated protein kinase $8 \mathrm{~b}$ & -5.355743879 & $1.18 \mathrm{E}-06$ \\
\hline NM_001080066 & g6pc3 & glucose 6 phosphatase, catalytic, 3 & 4.465924297 & $9.85 \mathrm{E}-08$ \\
\hline
\end{tabular}

essential for the activation of Wnt, JNK, and Notch signaling by regulating endosomal $\mathrm{pH}$ [17]. As per the above observations, biophysical and molecular approaches were used to address the ion nature and respective ion transporters involved in regeneration in an adult vertebrate (zebrafish). Our results suggested that V-ATPase is down-regulated, and these ATPases may be involved in the retinal degeneration in mutant zebrafish.

Fifteen genes are involved in the glycolysis/gluconeogenesis pathway, and they are down-regulated in mutant zebrafish except for the g6pc3 gene, which is up-regulated. It is a central pathway that produces important precursor metabolites, namely, six-carbon compounds of glucose-6P and fructose-6P and three-carbon compounds of glycerone-P, glyceraldehyde-3P, glycerate-3P, phosphoenolpyruvate, and pyruvate [18]. Gluconeogenesis is a synthesis pathway of glucose from noncarbohydrate precursors. It is essentially a reversal of glycolysis, with minor variations of alternative paths [19]. Glucose 6 phosphatase dehydrogenase (G6PDH) activity is regulated by the $\mathrm{NADP}^{+} / \mathrm{NADPH}$ ratio; $\mathrm{NADPH}$ inhibits its activity, whereas $\mathrm{NADP}^{+}$is required for its proper active conformation [20]. In the non-oxidative part of the pentose phosphate pathway (PPP), Ru5P is converted into ribose-5-phosphate (R5P) by ribulose-5-phosphate isomerase (RPIA), and R5P may re-enter the glycolytic pathway when converted into fructose-6-phosphate (F6P) or glyceraldehyde-3-phosphate (G3P) [21]. Increased flux of glucose through the pentose phosphate pathways can have a neuroprotective function [22]. All the glycolysis/gluconeogenesis genes are downregulated in the mutant zebrafish and might be involved in the retinal degeneration mechanism.

Twenty-four genes are involved in insulin signaling pathways, and they are down-regulated in mutant zebrafish. Our results showed that all the insulin signaling pathway genes are downregulated in the mutant zebrafish and may be involved in the retinal degeneration mechanism. Meanwhile, other pathways are also downregulated, including pyruvate metabolism, oxidative phosphorylation, TCA cycle pathways, pyruvate metabolic processes, and proton-transporting ATP synthase complexes, which reflects a decrease in the need for mitochondrial oxidative capacity in dedifferentiating cells. This is analogous to the processes of somatic and 


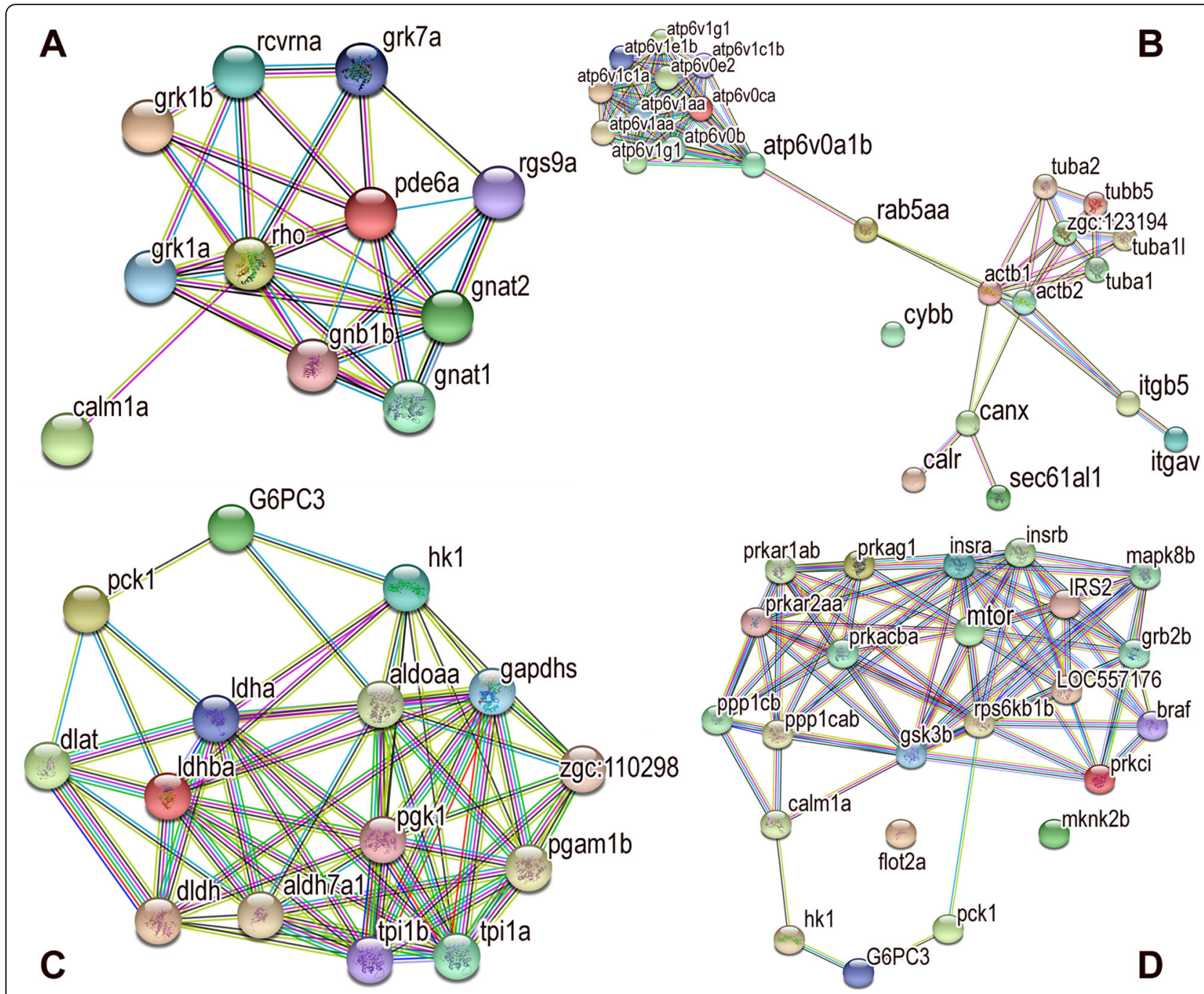

Fig. 6 The gene network analysis and interaction subnetworks. a Phototransduction pathway; b The phagosome pathway; c The glycolysis/ gluconeogenesis pathway; D The insulin signaling pathway subnetwork

oncogenic cellular reprogramming to a pluripotent state, in which reprogrammed cells undergo metabolic "rewiring" that reduces both mitochondrial content and oxidative phosphorylation capacity [23].

The detailed description of the up-regulated genes presented in the Additional file 1. Here, 18 notable upregulated genes that might be most related to the retinal degenerative process. Calhm2 (calcium homeostasis modulator family member 2) is activated by membrane depolarization, although its kinetic responses are distinct [24]. Calhm2 and connexins have similar structural features that confer both shared and distinct functional properties. They act as a sensor of extracellular $\mathrm{Ca}^{2+}$ in the brain; they may also participate in similar signaling functions in the retina [25]. The tnmd (tenomodulin) gene increases VEGF-A (vascular endothelial growth factor A) production, initiates the VEGFR (vascular endothelial growth factor receptor) signaling pathway, and leads to enhanced angiogenesis [26]. Rosenthal et al. suggested that the fgflb (fibroblast growth factor $1 \mathrm{~b}$ ) gene increases the L-type $\mathrm{Ca}^{2+}$ channel [27] activity of retinal pigment epithelium (RPE) cells, resulting in an increase of VEGF-A secretion from RPE cells [28]. Yun et al. $[29,30]$ also proposed that elevated TNF (Tumor necrosis factor) levels have been associated with different autoimmune diseases, and deregulation of tnfrsfla (TNF receptor superfamily member $1 \mathrm{~A}$ ) expression and signaling can lead to chronic inflammation and tissue damage. The role of the klf1 (kruppel like factor 1) gene in zebrafish comprises hematopoiesis, blood vessel function, and fin and epidermal development [31]. The pla2g12a (Phospholipase A2 Group 12A) gene is up-regulated in inflammation and atherosclerosis [32]. Deblandre et al. [33] suggested that neurl2 (neuralized-like protein 2) interacts with XDelta1 (xenopus delta1) and regulates Notch signaling. This signaling is involved in pathologic 
angiogenesis [34, 35], which is associated with tumor growth and ischemic stroke [36]. Ding et al. [37] suggested that phosphorylation of the plek (pleckstrin) gene increases proinflammatory cytokine secretion by mononuclear phagocytes in diabetes mellitus. The skap1 (src kinase associated phosphoprotein 1) gene plays a role in physiological retinal angiogenesis and the pathogenesis of retinal neovascularization [38]. The scgn (secretagogin) gene is a secthe reted calciumbinding protein found in the cytoplasm. It is related to calbindin D-28 K and calretinin. This protein is thought to be involved in potassium chloride (KCL)-stimulated calcium flux and cell proliferation [39]. Deangelis et al. [40] suggested that the HtrA Serine Peptidase 1 gene alters the risk of neovascular age-related macular degeneration. The tspan13a (tetraspanin 13a) gene defects affecting this protein cause a variety of progressive retinal degenerations in humans and mice and illustrate its importance for the formation and long-term stability of outer photoreceptor segments [41]. Xu et al. [23] suggested that lysosomal tspan13a gene is associated with retinal degeneration. The casp6 (caspase-6) gene is involved in neuronal apoptosis and the regenerative failure of injured retinal ganglion cells [42]. Ratnayaka et al. [43] proposed that app (amyloid beta) is involved in retinal degeneration. Overall, the gene network results suggested that most of the pathway genes interacted directly or indirectly with each other and were involved in specific cascade signaling pathways in retinal degeneration.

Our data strongly indicate that, among these genes, calcium-binding proteins, neural damage proteins, peptidase proteins, immunological proteins, and apoptosis proteins are mostly involved in retinal and neural degeneration.

Study limitations:

1. The small sample size of three Pde6c mutant and three control zebrafish retina datasets (Table 5) is a limitation of the current study, while this number is still sufficient for the useful analysis more substantial cohort of samples will allow identifying

Table 5 Detailed information of datasets of zebrafish (pde6c mutant and wildtype)

\begin{tabular}{llll}
\hline Bio Sample & Sample name & MBytes & zebrafish \\
\hline SRR5833546 & SAMN07358654 & 8838 & pde6c mutant \\
SRR5833545 & SAMN07358655 & 8774 & pde6c mutant \\
SRR5833544 & SAMN07358656 & 9229 & pde6c mutant \\
SRR5833543 & SAMN07358652 & 9321 & wildtype \\
SRR5833542 & SAMN07358653 & 8084 & wildtype \\
SRR5833541 & SAMN07358651 & 9611 & wildtype \\
\hline
\end{tabular}

the genes that were not detected as DEGs in the current work.

2. While the nature of the mutant Pde6c gene restricts its effect to photoreceptor cells, however, we cannot definitively exclude unknown expression or roles of pde6c in other cell types as the mutation is global and not tissue specific.

\section{Conclusion}

In conclusion, the gene expression studies in eye tissue are an initial step in determining functions for putatively associated retinal and neural degeneration risk genes. The RNA-Seq transcriptome data analysis showed the gene expression profile between mutant and wild-type zebrafish models of retinal degeneration. The analysis of mutant versus wild-type zebrafish retina data gives insight into potential genes and pathways that may be targeted in future therapeutic studies and expands the knowledge of the progression of retinal degeneration.

\section{Methods}

Data quality and preprocessing

The RNA-Seq paired-end zebrafish (Danio rerio) wild and pde6c mutant retina data (SRP112616) were acquired from the National Centre for Biotechnology Information-Sequence Read Archive (NCBI-SRA; http://www.ncbi.nlm.nih.gov/sra) using the SRA Toolkit (https://www.ncbi.nlm.nih.gov/sra/docs/toolkitsoft/) with a prefetch function, save for one file (SRR5833546). The three paired SRA files (each group) were converted into fastq files (six files) with fastq-dump and split-files functions (Table 5). Initially, we performed a visualization of the quality of all datasets before and after trimming the adaptors and going through the preprocessing steps by using the FastQC tool (https://www.bioinformatics.babraham.ac.uk/projects/fastqc/) [44]. Finally, we removed any low-quality reads by trimming the bases from the 3 ' and $5^{\prime}$ ends and maintaining a Phred-score $\leq 30$ using the Trimmomatic-0.36 tool [45]. After cleaning and trimming of low-quality reads and adaptor removal, more than $96 \%$ of good quality reads in each stage were retained. These cleaned reads were used for further transcriptome assembly analysis.

\section{Reference-based assembly}

All the datasets were assembled separately with a reference genome (zebrafish) using Bowtie 1.2.2 software [46]. Initially, Bowtie makes an indexes of genome file and align short reads to reference genome (Dani rerio: GRCz11,2017). Then, RSEM (RNA-Seq by Expectation-Maximization) [47] was used to estimate the number of RNA-Seq fragments that map to each contig with gene annotations in a GTF file. Because the abundance of individual transcripts may significantly differ between samples, the reads from each sample 
must be examined separately, resulting in sample-specific abundance values.

\section{Identification of differentially expressed genes (DEGs)}

The Bioconductor tool was used with the edgeR package to analyze differential expression analysis in the assembled transcriptome $[48,49]$. The wild and Pde6c mutant Danio rerio comparison transcript counts (matrix file) were used for differential gene expression with the Empirical Analysis of Digital Gene Expression in R (edgeR) package of Bioconductor with primary parameters like the false discovery rate (FDR), log fold change (logFC), log counts per million $(\log C \mathrm{PM})$, and $p$-value $[48,50]$. Unigenes with $p$ values less than $0.001(p<0.001)$ and fold change of more than $4(\operatorname{logFC}>4)$ were considered significantly differentially expressed. The differentially expressed genes were visualized by volcano plot, MA plot and heatmaps respectively. A volcano plot is a type of scatterplot that is used to quickly identify changes in large datasets composed of replicate data. A heatmap is a graphical representation of data that uses a color-coding system to represent different values. It combines a measure of statistical significance from a statistical test ( $p$-value from an analysis of variance [ANOVA] model) with the magnitude of the change, enabling quick visual identification of those data points (genes) that display large magnitude changes that are also statistically significant [51]. An MA plot is an application of a Bland-Altman plot for a visual representation of genomic data [52]. The log2 fold change for a particular comparison is plotted on the $y$-axis and the average of the counts normalized by size factor is shown on the $\mathrm{x}$-axis ("M" for minus, because a log-ratio is equal to log minus log, and "A" for average).

\section{Functional annotation}

Gene ontology (GO) Enrichment Analysis (http://geneontology.org/page/go-enrichment-analysis) and DAVID annotation (https://david.ncifcrf.gov/) was used for functional annotation and pathway analysis, such as for the MFs, BPs, and CCs and KEGG pathways. GO terms with FDR $(\mathrm{q}<$ $0.05)$ were considered significantly enriched within the gene set $[53,54]$.

\section{Gene network analysis}

We performed protein-protein network analysis for all the DEGs using the STRING 10.5 database (https://string-db. org/), a useful tool for understanding metabolic pathways, and predicting or developing genotype-phenotype associations [55].

\section{Statistical analysis}

All the numeric values were expressed as the mean \pm standard deviation (SD) of the respective groups. Statistical analyses were performed using Trinity software (https://github.com/trinityrnaseq/trinityrnaseq/wiki). Student $t$-tests and Benjamini-Hochberg corrections (FDR) were used. A $p$-value of less than 0.001 was considered significant.

\section{Supplementary information}

Supplementary information accompanies this paper at https://doi.org/10. 1186/s12864-020-6550-z.

Additional file 1: FigureS1. Gene-gene interaction network of all differentially expressed genes. We mapped the phagosome (red), glycolysis/ gluconeogenesis (blue), and insulin signaling (green) pathway genes' interaction in the global network.

\section{Abbreviations}

APP: Amyloid beta; BP: Biological process; CALHM2: Calcium homeostasis modulator family member 2; CASP6: Caspase-6; CC: Cellular component; CGMP: Cyclic guanosine monophosphate; CYBB: Cytochrome b-245 beta; DAVID: Database for annotation, visualization, and integrated discovery; DEGs: Differentially expressed genes; edgeR: Empirical analysis of Digital Gene Expression in R; F6P: Fructose-6-phosphate; FDR: False discovery rate; FGF1B: Fibroblast growth factor 1b; FLOT2A: Flotillin-2a; G3P: Glyceraldehyde3-phosphate; G6PDH: Glucose 6 phosphatase dehydrogenase; GO: Gene ontology; KCL: Potassium chloride; KEGG: Kyoto Encyclopedia of Genes and Genomes; KLF1: Kruppel like factor 1; logCPM: Log counts per million; logFC: Log fold change; MF: Molecular function; MKNK2B: MAPK interacting serine/threonine kinase 2b; NCBI: National Centre for Biotechnology Information; NEURL2: Neuralized-like protein 2; PDE6C: Phosphodiesterase 6c; PLA2G12A: Phospholipase A2 Group 12A; PLEK: Pleckstrin; R5P: Ribose-5phosphate; RP: Retinitis pigmentosa; RPE: Retinal pigment epithelium; RSEM: RNA-Seq by Expectation-Maximization; SCGN: Secretagogin; SD: Standard deviation; SKAP1: Src kinase associated phosphoprotein 1; SRA: Sequence Read Archive; TNF: Tumour necrosis factor; TNFRSF1A: TNF receptor superfamily member 1A; TSPAN13A: Tetraspanin 13a; VEGFA: Vascular endothelial growth factor-A; VEGFR: Vascular endothelial growth factor receptor; XD1: Xenopus delta1

\section{Acknowledgments}

The authors wish to acknowledge the contribution of the Center for Biomedical Informatics (CBMI), University of Missouri (Columbia, MO, USA), which provided computer application facilities. Ms. Amy Folkerts A. and Ms. Catherine Brooks J. (University of Missouri, Department of Ophthalmology Columbia, Missouri, USA) for editing and language corrections.

\section{Authors' contributions}

The study was conceived and designed by MSS, AL, and HH. MSS performed the quality check, reference genome assembly, gene expression analysis, gene ontology, functional pathway analysis, and gene network analysis. AL conducted figure design and statistical analysis. AB provided independent data validation and additional $\mathrm{R}$ programming. The manuscript was written by MSS, AL, and $\mathrm{HH}$ and critically revised by $\mathrm{HH}$. All authors reviewed and accepted the final version of the manuscript.

\section{Funding}

This project was supported by the University of Missouri startup funds ( $\mathrm{Hu}$ Huang) and an NIH grant (EY027824). The funding bodies played no role in the design of the study and collection, analysis, and interpretation of data and in writing the manuscript.

\section{Availability of data and materials}

The datasets SRP112616 analyzed during the current study are available in the National Centre for Biotechnology Information-Sequence Read Archive (NCBI-SRA) repository, https://www.ncbi.nlm.nih.gov/sra/?term=SRP112616. All data generated or analyzed during this study are included in this published article and its supplementary information files. The raw files of the analysis pipeline output and information on the analysis pipeline can be provided on reasonable request to the corresponding author. 


\section{Ethics approval and consent to participate}

Hu Huang's research group is approved for vertebrae animal research under Institutional Animal Care and Use Committee of University of Missouri School of Medicine (protocol number: 9520), however, as the current study was conducted on publicly available RNA-seq datasets (SRP112616), no additional ethical approval was required.

\section{Consent for publication}

Not applicable.

\section{Competing interests}

The authors declare that they have no competing interests.

Received: 29 May 2019 Accepted: 31 January 2020

Published online: 07 February 2020

\section{References}

1. Brill E, Malanson KM, Radu RA, Boukharov NV, Wang Z, Chung HY, Lloyd MB, Bok D, Travis GH, Obin M, et al. A novel form of transducin-dependent retinal degeneration: accelerated retinal degeneration in the absence of rod transducin. Invest Ophthalmol Vis Sci. 2007;48(12):5445-53.

2. Rattner $A$, Sun $H$, Nathans J. Molecular genetics of human retinal disease. Annu Rev Genet. 1999;33:89-131.

3. Hartong DT, Berson EL, Dryja TP. Retinitis pigmentosa. Lancet. 2006; 368(9549):1795-809.

4. Chinchore Y, Mitra A, Dolph PJ. Accumulation of rhodopsin in late endosomes triggers photoreceptor cell degeneration. PLoS Genet. 2009;5(2): e1000377.

5. Zhang L, Xiang L, Liu Y, Venkatraman P, Chong L, Cho J, Bonilla S, Jin ZB, Pang $C P$, Ko KM, et al. A naturally-derived compound Schisandrin B enhanced light sensation in the pde6c Zebrafish model of retinal degeneration. PLoS One. 2016;11(3):e0149663.

6. Gross JV, Perkins BD. Zebrafish mutants as models for congenital ocular disorders in humans. Mol Reprod Dev. 2008;75(3):547-55.

7. Stearns G, Evangelista M, Fadool JM, Brockerhoff SE. A mutation in the cone-specific pde6 gene causes rapid cone photoreceptor degeneration in zebrafish. J Neurosci. 2007:27(50):13866-74.

8. Warren R, Molday RS. Regulation of the rod photoreceptor cyclic nucleotide-gated channel. Adv Exp Med Biol. 2002;514:205-23.

9. Dryja TP, Rucinski DE, Chen SH, Berson EL. Frequency of mutations in the gene encoding the alpha subunit of rod cGMP-phosphodiesterase in autosomal recessive retinitis pigmentosa. Invest Ophthalmol Vis Sci. 1999; 40(8):1859-65.

10. Gopalakrishna KN, Boyd K, Artemyev NO. Mechanisms of mutant PDE6 proteins underlying retinal diseases. Cell Signal. 2017;37:74-80.

11. Chang B, Grau T, Dangel S, Hurd R, Jurklies B, Sener EC, Andreasson S, Dollfus $H$, Baumann B, Bolz S, et al. A homologous genetic basis of the murine cpfl1 mutant and human achromatopsia linked to mutations in the PDE6C gene. Proc Natl Acad Sci U S A. 2009;106(46):19581-6.

12. Thiadens AA, den Hollander Al, Roosing S, Nabuurs SB, Zekveld-Vroon RC, Collin RW, De Baere E, Koenekoop RK, van Schooneveld MJ, Strom TM, et al. Homozygosity mapping reveals PDE6C mutations in patients with earlyonset cone photoreceptor disorders. Am J Hum Genet. 2009;85(2):240-7.

13. Zhang $L$, Zhang $X$, Zhang G, Pang $C P$, Leung $Y F$, Zhang $M$, Zhong $W$. Expression profiling of the retina of pde6c, a zebrafish model of retinal degeneration. Scientific data. 2017;4:170182.

14. Garcia-Campos MA, Espinal-Enriquez J, Hernandez-Lemus E. Pathway analysis: state of the art. Front Physiol. 2015;6:383.

15. Ma Z, Siebert AP, Cheung KH, Lee RJ, Johnson B, Cohen AS, Vingtdeux V, Marambaud P, Foskett JK. Calcium homeostasis modulator 1 (CALHM1) is the pore-forming subunit of an ion channel that mediates extracellular Ca2+ regulation of neuronal excitability. Proc Natl Acad Sci U S A. 2012; 109(28):E1963-71.

16. Nuckels RJ, Ng A, Darland T, Gross JM. The vacuolar-ATPase complex regulates retinoblast proliferation and survival, photoreceptor morphogenesis, and pigmentation in the zebrafish eye. Invest Ophthalmol Vis Sci. 2009;50(2):893-905.

17. Cruciat CM, Ohkawara B, Acebron SP, Karaulanov E, Reinhard C, Ingelfinger D, Boutros M, Niehrs C. Requirement of prorenin receptor and vacuolar $\mathrm{H+-}$ ATPase-mediated acidification for Wnt signaling. Science. 2010;327(5964): 459-63.
18. Rocha F, Dias J, Engrola S, Gavaia P, Geurden I, Dinis MT, Panserat S. Glucose metabolism and gene expression in juvenile zebrafish (Danio rerio) challenged with a high carbohydrate diet: effects of an acute glucose stimulus during late embryonic life. Brit J Nutr. 2015;113(3):403-13.

19. Chen Y-J, Zhang T-Y, Chen H-Y, Lin S-M, Luo L, Wang D-S. An evaluation of hepatic glucose metabolism at the transcription level for the omnivorous GIFT tilapia, Oreochromis niloticus during postprandial nutritional status transition from anabolism to catabolism. Aquaculture. 2017;473:375-82.

20. Patra KC, Hay N. The pentose phosphate pathway and cancer. Trends Biochem Sci. 2014;39(8):347-54.

21. Bouzier-Sore AK, Bolanos JP. Uncertainties in pentose-phosphate pathway flux assessment underestimate its contribution to neuronal glucose consumption: relevance for neurodegeneration and aging. Front Aging Neurosci. 2015;7:89.

22. Schubert D. Glucose metabolism and Alzheimer's disease. Ageing Res Rev 2005;4(2):240-57.

23. Xu H, Lee SJ, Suzuki E, Dugan KD, Stoddard A, Li HS, Chodosh LA, Montell C. A lysosomal tetraspanin associated with retinal degeneration identified via a genome-wide screen. EMBO J. 2004;23(4):811-22.

24. Ma ZM, Tanis JE, Taruno A, Foskett JK. Calcium homeostasis modulator (CALHM) ion channels. Pflug Arch Eur J Phy. 2016;468(3):395-403.

25. Ma B, Xiang Y, An L. Structural bases of physiological functions and roles of the vacuolar H(+)-ATPase. Cell Signal. 2011;23(8):1244-56.

26. Hakuno D, Kimura N, Yoshioka M, Fukuda K. Role of angiogenetic factors in cardiac valve homeostasis and disease. J Cardiovasc Transl Res. 2011;4(6): 727-40.

27. Saddala MS, Kandimalla R, Adi PJ, Bhashyam SS, Asupatri UR. Novel 1, 4dihydropyridines for L-type calcium channel as antagonists for cadmium toxicity. Sci Rep. 2017;7:45211.

28. Rosenthal R, Heimann H, Agostini H, Martin G, Hansen LL, Strauss O. Ca2+ channels in retinal pigment epithelial cells regulate vascular endothelial growth factor secretion rates in health and disease. Mol Vis. 2007;13:443-56.

29. Dong Y, Fischer R, Naude PJ, Maier O, Nyakas C, Duffey M, Van der Zee EA, Dekens D, Douwenga W, Herrmann A, et al. Essential protective role of tumor necrosis factor receptor 2 in neurodegeneration. Proc Natl Acad Sci U S A. 2016;113(43):12304-9.

30. Saddala MS, Huang $H$. Identification of novel inhibitors for TNFalpha, TNFR1 and TNFalpha-TNFR1 complex using pharmacophore-based approaches. J Transl Med. 2019;17(1):215

31. Oates AC, Pratt SJ, Vail B, Yan Y, Ho RK, Johnson SL, Postlethwait JH, Zon LI. The zebrafish klf gene family. Blood. 2001;98(6):1792-801.

32. Nicolaou A, Northoff BH, Sass K, Ernst J, Kohlmaier A, Krohn K, Wolfrum C, Teupser D, Holdt LM. Quantitative trait locus mapping in mice identifies phospholipase Pla2g12a as novel atherosclerosis modifier. Atherosclerosis. 2017;265:197-206

33. Deblandre GA, Lai EC, Kintner C. Xenopus neuralized is a ubiquitin ligase that interacts with XDelta1 and regulates notch signaling. Dev Cell. 2001; 1(6):795-806.

34. Latha MS, Saddala MS. Molecular docking based screening of a simulated HIF-1 protein model for potential inhibitors. Bioinformation. 2017;13(11): 388-93.

35. Mukund V, Saddala MS, Farran B, Mannavarapu M, Alam A, Nagaraju GP. Molecular docking studies of angiogenesis target protein HIF-1alpha and genistein in breast cancer. Gene. 2019;701:169-72.

36. Rehman $\mathrm{AO}$, Wang $\mathrm{CY}$. Notch signaling in the regulation of tumor angiogenesis. Trends Cell Biol. 2006;16(6):293-300.

37. Ding Y, Kantarci A, Badwey JA, Hasturk H, Malabanan A, Van Dyke TE. Phosphorylation of pleckstrin increases proinflammatory cytokine secretion by mononuclear phagocytes in diabetes mellitus. J Immunol (Baltimore, Md : 1950). 2007;179(1):647-54.

38. Werdich $X Q$, Penn JS. Specific involvement of SRC family kinase activation in the pathogenesis of retinal neovascularization. Invest Ophthalmol Vis Sci. 2006;47(11):5047-56.

39. Wagner L, Oliyarnyk O, Gartner W, Nowotny P, Groeger M, Kaserer K, WaldhausI W, Pasternack MS. Cloning and expression of secretagogin, a novel neuroendocrine- and pancreatic islet of Langerhans-specific Ca2+ -binding protein. J Biol Chem. 2000;275(32):24740-51.

40. Deangelis MM, Ji F, Adams S, Morrison MA, Harring AJ, Sweeney MO, Capone A Jr, Miller JW, Dryja TP, Ott J, et al. Alleles in the HtrA serine peptidase 1 gene alter the risk of neovascular age-related macular degeneration. Ophthalmology. 2008;115(7):1209-15 e1207. 
41. Kohl S, Giddings I, Besch D, Apfelstedt-Sylla E, Zrenner E, Wissinger B. The role of the peripherin/RDS gene in retinal dystrophies. Acta Anat (Basel). 1998;162(2-3):75-84.

42. Monnier PP, D'Onofrio PM, Magharious M, Hollander AC, Tassew N, Szydlowska K, Tymianski M, Koeberle PD. Involvement of caspase-6 and caspase-8 in neuronal apoptosis and the regenerative failure of injured retinal ganglion cells. J Neurosci. 2011;31(29):10494-505.

43. Ratnayaka JA, Serpell LC, Lotery AJ. Dementia of the eye: the role of amyloid beta in retinal degeneration. Eye (Lond). 2015;29(8):1013-26.

44. Saddala MS, Lennikov A, Mukwaya A, Fan L, Hu Z, Huang H. Transcriptomewide analysis of differentially expressed chemokine receptors, SNPs, and SSRs in the age-related macular degeneration. Hum Genomics. 2019;13(1):15.

45. Bolger AM, Lohse M, Usadel B. Trimmomatic: a flexible trimmer for Illumina sequence data. Bioinformatics. 2014;30(15):2114-20.

46. Langmead B, Trapnell C, Pop M, Salzberg SL. Ultrafast and memory-efficient alignment of short DNA sequences to the human genome. Genome Biol. 2009;10(3):R25

47. Wu Y, Yang H, Liu H, Yang Z, Zhu M, Pan X, Huang T, Zou K, Bai J, Ma Y, et al. Research of herb components on scavenging harmful components and reducing cytotoxicity of cigarette smoke. Zhongguo Zhong Yao Za Zhi. 2011;36(22):3184-8.

48. Anders $\mathrm{S}$, Huber W. Differential expression analysis for sequence count data. Genome Biol. 2010;11(10):R106.

49. Robinson MD, McCarthy DJ, Smyth GK. edgeR: a bioconductor package for differential expression analysis of digital gene expression data. Bioinformatics. 2010;26(1):139-40.

50. Robinson MD, Oshlack A. A scaling normalization method for differential expression analysis of RNA-seq data. Genome Biol. 2010;11(3):R25.

51. Li WT. Volcano Plots in Analyzing Differential Expressions with Mrna Microarrays. J Bioinf Comput Biol. 2012;10(6):1231003.

52. Love Ml, Anders S, Kim V, Huber W. RNA-Seq workflow: gene-leve exploratory analysis and differential expression. F1000Research. 2015;4:1070.

53. Huang DW, Sherman BT, Tan Q, Kir J, Liu D, Bryant D, Guo Y, Stephens R, Baseler MW, Lane HC, et al. DAVID Bioinformatics Resources: expanded annotation database and novel algorithms to better extract biology from large gene lists. Nucleic Acids Res. 2007;35(Web Server issue):W169-75.

54. Saddala MS, Lennikov A, Grab DJ, Liu GS, Tang S, Huang H. Proteomics reveals ablation of PIGF increases antioxidant and neuroprotective proteins in the diabetic mouse retina. Sci Rep. 2018;8(1):16728.

55. Wang Z, Gerstein M, Snyder M. RNA-Seq: a revolutionary tool for transcriptomics. Nat Rev Genet. 2009;10(1):57-63.

\section{Publisher's Note}

Springer Nature remains neutral with regard to jurisdictional claims in published maps and institutional affiliations.

Ready to submit your research? Choose BMC and benefit from:

- fast, convenient online submission

- thorough peer review by experienced researchers in your field

- rapid publication on acceptance

- support for research data, including large and complex data types

- gold Open Access which fosters wider collaboration and increased citations

- maximum visibility for your research: over $100 \mathrm{M}$ website views per year

At $\mathrm{BMC}$, research is always in progress.

Learn more biomedcentral.com/submissions 